\title{
Reduction of disc brake fading using both design and material optimization
}

\author{
Jad Kalaaji ${ }^{1}$, and Mervat Madi $^{2}$ \\ ${ }^{1}$ Lebanese University, Faculty of Engineering, Mechanical Engineering Department, Beirut, Lebanon \\ ${ }^{2}$ American University of Beirut, Research Department, Beirut, Lebanon
}

\begin{abstract}
This study is to investigate, under extreme working conditions, the trend of the thermomechanical behavior of different brake rotors by means of FEM thermo-mechanical coupled analyses. More efficient designs are suggested and compared to existing ones, based on cooling capability.
\end{abstract}

\section{Introduction}

The principle used in braking is to convert the kinetic energy of a vehicle into heat energy mainly dissipated by convection. However, on high-demand braking, convection is unable to dissipate all the heat, causing overheating of the components. With this aim, innovative discs have been designed in this project to improve the convection of disc rotors.

\section{Working conditions}

The analysed brake discs have been subjected to very hard conditions using an extreme fading test [1,2]. This test consists of two consecutive braking cycles, with the number of cycles being restricted by computational stress. Each braking cycle consists of accelerating to a velocity of $160 \mathrm{Km} / \mathrm{h}$ and retaining this speed for 32 seconds, then braking with a constant deceleration of $5.886 \mathrm{~m} / \mathrm{s}^{2}$ until making a complete stop during 7.374 seconds. These data represent the working conditions that the rotors will undergo during the test and that will be simulated using a FEM software in order to find the temperature distributions and compare the different rotor designs with each other. At the end of the braking test, we will deduce which rotor is considered better than all the others in terms of the temperature results obtained.

In table 1, the most important data of the braking test are mentioned. The ventilated discs shown in figure 1 have, respectively, straight vanes, pillar-shaped vanes (DTDP), curved vanes, and the three others, are new designs we invented named new design 1, 2 and 3 . As for the disc material, we chose gray cast iron commonly used. All the main thermal and mechanical properties are stored in table 2 [3-5]. Finally, we tried steel to see the difference in behaviors.
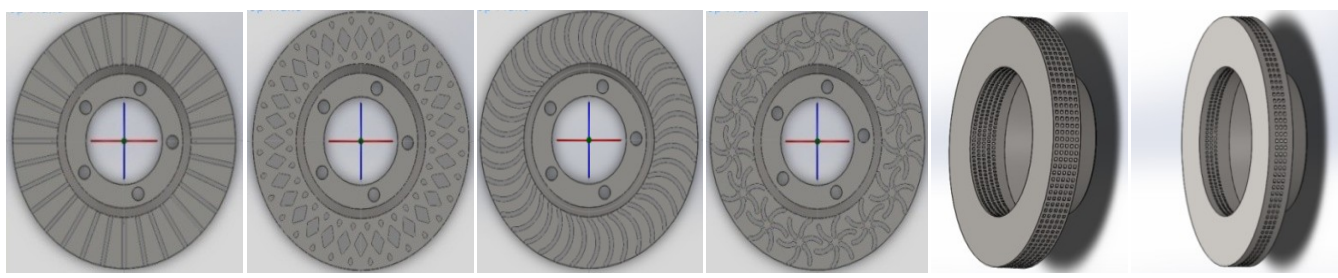

Fig. 1. Section views of the different discs, left: three existing designs, right: three new designs.

\section{Heat flux and brake force inputs}

\subsection{Heat Flux}

Basing of the law of conservation of energy, it can be assumed that almost all the kinetic energy of the vehicle is equal to the heat generated after vehicle stops. In this study, the thermal conductivity of the pads is considered much smaller than the one of the disc [6,7] because, in real life heat must not conduct to other braking components such as the brake fluid to prevent vapor formation in it. For this reason, the heat generated is considered entirely absorbed by the disc.

During a braking, the variation of the kinetic energy in one wheel turn is calculated as:

$$
\left.\Delta E=\frac{1}{2} m . \quad V_{\mathrm{f}}^{2}-V_{\mathrm{i}}^{2}\right) ;
$$


where $V_{\mathrm{f}}$ and $V_{\mathrm{i}}$ are, respectively, the final and initial velocity during one wheel rotation. Since the braking is a uniformly decelerated motion, $\left(V_{\mathrm{f}}{ }^{2}-V_{\mathrm{i}}{ }^{2}\right)$ is constant and consequently also $\Delta E$ is constant at every single wheel rotation:

$$
\Delta E=\frac{1}{2} m \cdot\left(V_{\mathrm{f}}^{2}-V_{\mathrm{i}}{ }^{2}\right)=\text { m.a. } C_{0}=\text { constant }=14347.125 \mathrm{~J} ;
$$

Neglecting both motion resistance and engine braking, the thermal energy, $\mathrm{Q}_{\text {wheel }}$, on a single front wheel during a single turn, is calculated [7] as a function of $\Delta E$ :

$$
Q_{\text {wheel }}=\frac{1}{2} \cdot f \cdot \Delta E=\text { constant }=\frac{1}{2} * 0.6 * 14347.125=4304.1375 \mathrm{~J} ;
$$

In order to simplify the setup of the boundary conditions, without affecting the results, it has been assumed that the heat flux is constant over a single wheel rotation and equal to:

$$
q=\frac{Q_{\text {wheel }}}{\Delta t}
$$

where $\Delta \mathrm{t}$ is the wheel turning time. The routine developed to simulate the relative rotation between pads and disc has required to calculate, from the beginning to the end of the braking, at every wheel turn, the specific heat flux as :

$$
q\left(S_{\mathrm{pad}}\right)=q \cdot \frac{1}{S_{\mathrm{pad}}}=\frac{Q_{\text {wheel }}}{\Delta t} \cdot \frac{1}{S_{\mathrm{pad}}} ;
$$

where $S_{\text {pad }}$ is the surface of the braking pad. And by considering the effect of other factors in decelerating the vehicle such as air resistance, engine braking and gearbox ratios, $40 \%$ of the deceleration are deducted from the brakes work.

\subsection{Braking forces}

During braking, normal $F_{n}$ and tangential $F_{t}$ forces on one front wheel are expressed as:

$$
\begin{gathered}
F_{\mathrm{n}}=f . m \cdot g \cdot \frac{1}{2} \cdot k=0.6 * 1250 * 9.81 * 0.5 * 1.1=4046.625 \mathrm{~N} ; \\
F_{\mathrm{t}}=F_{\mathrm{n}} . f_{\mathrm{ad}}=4046.625 * 0.85=3439.63125 \mathrm{~N} ;
\end{gathered}
$$

The braking torque $\mathrm{M}_{\mathrm{b}}$ applied to one wheel and the normal braking force on one pad $\mathrm{F}_{\text {pad }}$ are calculated as:

$$
\begin{aligned}
M_{\mathrm{b}} & =F_{t} \cdot \frac{C_{0}}{2 \Pi} ; \\
\mathrm{F}_{\text {pad }} & =\frac{\mathrm{Mb}_{\mathrm{b}}}{\mathrm{f}_{\mathrm{f}} \cdot \mathrm{d}} \cdot \frac{1}{2} ;
\end{aligned}
$$

Table 1. Brake fading test input data.

\begin{tabular}{|c|c|}
\hline Input data & Value \\
\hline Vehicle mass, $m(\mathrm{Kg})$ & 1250 \\
\hline Initial velocity, $V_{i}(\mathrm{~m} / \mathrm{s})$ & 44.444 \\
\hline Deceleration, $a\left(\mathrm{~m} / \mathrm{s}^{2}\right)$ & 5.886 \\
\hline Tire rolling circumference, $C_{0}(\mathrm{~m})$ & 1.95 \\
\hline Tires and road adhesion coefficient, $f_{a d}$ & 0.85 \\
\hline Friction coefficient between pad and disc, $f_{f}$ & 0.43 \\
\hline $\begin{array}{c}\text { Vehicle inertia coefficient, } k \\
\text { Dynamic load distribution coefficient on }\end{array}$ & 0.6 \\
\hline \begin{tabular}{c} 
front wheels, $f$ \\
\hline
\end{tabular}
\end{tabular}

Table 2. Properties of the material in use at $20^{\circ} \mathrm{C}$

\begin{tabular}{|c|c|}
\hline Property & Value \\
\hline Density, $\rho\left(\mathrm{Kg} / \mathrm{m}^{3}\right)$ & $7096.25-7200$ \\
\hline Thermal expansion coefficient, $\mathrm{a}_{1}\left(10^{-5} /{ }^{\circ} \mathrm{C}\right)$ & 1.63 \\
\hline Elastic modulus, $\mathrm{E}(\mathrm{GPa})$ & $40-73$ \\
\hline Poisson's ratio, $v$ & 0.29 \\
\hline Thermal conductivity, $\lambda(\mathrm{W} / \mathrm{K} . \mathrm{m})$ & $40.23-56.54$ \\
\hline Specific heat capacity, $\mathrm{C}(\mathrm{J} / \mathrm{Kg} . \mathrm{K})$ & $475.2-745.98$ \\
\hline Melting point, $\left({ }^{\circ} \mathrm{C}\right)$ & 855 \\
\hline Compressive strength, $(\mathrm{MPa})$ & \\
\hline
\end{tabular}

\section{Setup of numerical analyses and benchmarking the software}

The fading test has been numerically simulated using a thermo-mechanical coupled analyses. During thermal analyses, heat flux and convective heat transfer are the boundary conditions. During the recovery time simulations, convection is the only applied boundary condition basing on the experiential formulas in the literature[8], and considering air temperature equal to $20^{\circ} \mathrm{C}$. Then, to setup the structural analysis, the temperature distribution over the disc at the end of the last thermal analysis and the braking forces on the pads have been imposed as boundary conditions.

Then, we benchmarked the FEM software with an experimental test using the machine shown in figure 2. For this reason, we executed the test on the machine and measured the temperature results, then we simulated the working 
conditions of the machine such as ambient temperature, weight of the disc, speed of rotation..., using the FEM software, and we obtained acceptable temperature results on both platforms. By that, we would have tested the validity of our code.

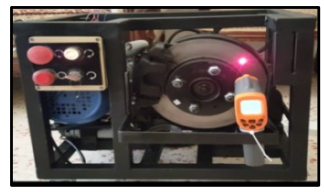

Fig. 2. Experimental test machine.

\section{Thermal results and conclusion}

For all the configurations, it can be observed that during braking, disks temperatures remarkably increase specially on the annular braking surface but remain lower than the melting point of cast iron in use. During the recovery stage, instead, the maximum temperatures decrease. Figure 3 shows the temperature maps on the discs after the first braking.
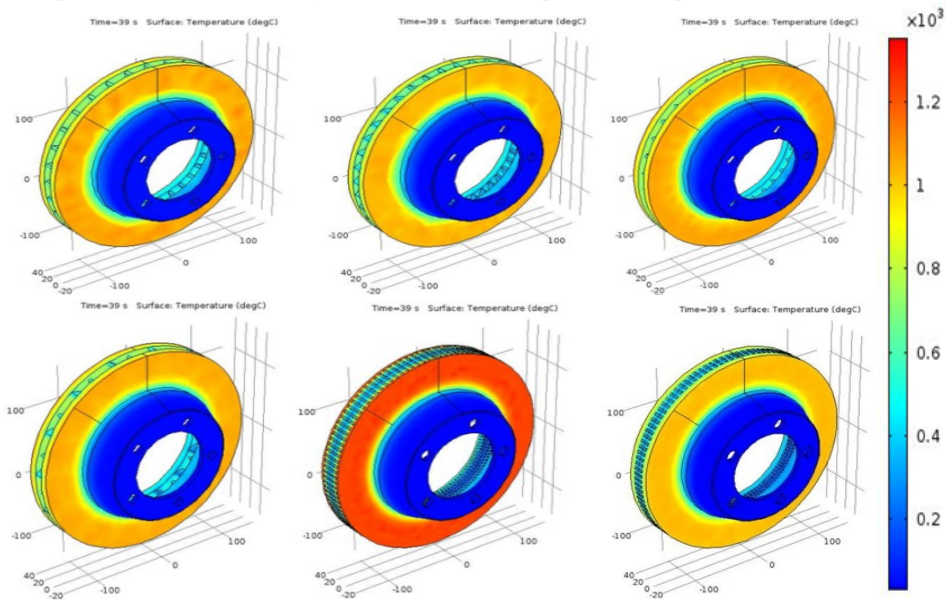

Fig. 3. Temperature distribution $\left(\times 10^{3}{ }^{\circ} \mathrm{C}\right)$ at the end of the first braking cycle $($ Time $=39 \mathrm{~s})$ on the external and internal surfaces of the straight vanes, curved vanes, DTDP, new design 1,2 and 3 respectively.

We can observe that, new design 2 resulted in higher temperatures on the annular surfaces. Then by investigating the temperatures after the following recovery, this disc showed the best cooling ability. For this reason, new design 3 overcame the maximum temperature problem by thickening the sides, and even though the cooling capacity decreased, but it remained better than the others.

By comparing the results, we conclude that the new design 3's cooling vanes tend to give us the lowest maximum temperatures. In addition, the cooling ability was seen best. Finally, we tried steel as disc material in order to see the difference in behaviors, and it was found that cast iron gave better temperature results. Also, maximum temperatures in case of steel were very close to the melting point. For these reasons, we considered cast iron as disc material.

\section{References}

[1] Brembo GT, Technical Information, (2014)

[2] C. Baron Saiz, T. Ingrassia, V. Nigrelli, V. Ricotta, Thermal stress analysis of different full and ventilated disc brakes , 34 (2015) 608-621; DOI: 10.3221/IGF-ESIS.34.67

[3] D. Holmgren, R. Kallbom, I.L. Svensson, Metall and Materal Trans. A, v38A, p268 (2007)

[4] McGraw-Hillbook company, NewYork, Black,P.H.,O.Eugene Adams, Machine design data book, (1996)

[5] R. Karwa, A textbook of machine design, (2002)

[6] Belhocine, A., Mostefa B., Simulation of fully coupled thermomechanical analysis of automotive brake discs,Simulation, 88.8 (2012) 921-935.

[7] Hwang, P., Wu, X., Investigation of temperature and thermal stress in ventilated disc brakebased on 3D thermomechanical coupling model, J. of mechanical science and technology, 24(1) (2010) 81-84.

[8] "Transmission de la chaleur" par Dr. Adel Mourtada et Pr. Gilbert MENGUY Beyrouth 1998, Département des Publications de l'Université Libanaise, Place du Musée. 